\section{B A Institute of \\ YK Business Administration \\ 六下 \\ Karachi \\ Leadership and Ideas for Tomorrow}

Business Review

Volume 9 Issue 2 July-December 2014

7-1-2014

\title{
Strategic management research: The missing linchpin in developing economy's context
}

\author{
Irfan Saleem \\ Institut de Recherche en Gestion des Organisations Université de Bordeaux, France
}

Follow this and additional works at: https://ir.iba.edu.pk/businessreview

Part of the Growth and Development Commons, Management Sciences and Quantitative Methods Commons, and the Strategic Management Policy Commons

(c) (7)

This work is licensed under a Creative Commons Attribution 4.0 International License.

\section{Recommended Citation}

Saleem, I. (2014). Strategic management research: The missing linchpin in developing economy's context. Business Review, 9(2), 97-105. Retrieved from https://doi.org/10.54784/1990-6587.1273

This article is brought to you by iRepository for open access under the Creative Commons Attribution 4.0 License and is available at https://ir.iba.edu.pk/businessreview/vol9/iss2/7. For more information, please contact irepository@iba.edu.pk. 


\title{
ARTICLE
}

\section{STRATEGIC MANAGEMENT RESEARCH: THE MISSING LINCHPIN IN DEVELOPING ECONOMY'S CONTEXT}

\author{
Irfan Saleem \\ Institut de Recherche en Gestion des Organisations \\ Université de Bordeaux, France
}

\begin{abstract}
Research is conducted to identify impact of adopting Strategic HRM on HR outcomes (i.e. job satisfaction and organizational commitment) and performance measures (i.e. organizational and, individual performance) in order to the fill empirical gap in developing economy's context. Cased based survey approach has been adopted to retrieve the evidence from companies. Three organizations are studied in depth to identify the evidence about strategic role of HRM. Objectivism has been adopted to test ontological assumption whereas positivism has been incorporated to test the epistemological assumption to prove the nature of reality about Strategic HRM. Results depict that effective Strategic HRM adoption can help companies to enhance the work attitudes' of staff along with company's performance. Study has extended universal perspective of Strategic HRM. Study accepts that HR paradigm is shifting in to prove $H R$ as strategic business partner in developing economies. Results reveal that Strategic HRM is positively associated with HR outcomes and performance measures and varies between companies of different sizes. Practitioners are encouraged to adopt Strategic HRM with the trust that company's performance will be improved by addressing the HR outcomes. Thus companies that align HR function and practices perform better and produce satisfied and committed employees for enhanced individual and organizational performance in developing economies like Pakistan.
\end{abstract}

Keywords: Strategic human resource management, job satisfaction, organizational commitment, individual performance and organizational performance

\section{Introduction}

Dramatic transform in the field of human resource management (HRM) in last few decades (Delery and Doty, 1996), has also shifted the trend of HRM research in developing economies like Pakistan to rethink about HR theories and models (Khilji \& Wang, 2006). However the recent HR studies (Saleem \& Khurshid, 2014; Saleem \& Saleem, 2014) in these economies tried to present that the same HR trends are being adopted without contextualization. This dilemma needed to be solved. This is because in reality it will not be possible for local organizations to adopt universal HR trends in local settings without contextualization (Khilji, 2003). Many studies have shown that Strategic HRM has a positive $\&$ direct impact on organization performance. Recently, researchers have begun to scrutinize 
the effect of SHRM on HR effectiveness and found that there exists negative bonding between Strategic HRM and HR (Delery, \& Doty, 1996; Wright, \& McMahan, 1992). In 2006, Khilji \& Wang claim that performance of the organization, depends on individual performance $\&$ if individual performance is improved then it subsequently bring a positive effect on the performance of the organization, that is linked with the individual attitude at work place. Therefore it is indeed a great need to underpin paradigm shift in the field of HR while keeping in view the contextual significance of mostly undocumented economies like Pakistan to explore missing linchpin. One of such research based initiative has been taken by emerging researcher like Khilji (2003). In her article Khilji addresses the research question i.e. Do Pakistani organizations need to adopt all trends in HR of developed economies? This highlights the research gap in developing economy's context. It is also focused by scholars to reconsider national culture, nature of political and socioeconomic realities of Pakistan at macro level, while also focusing on organizational structures and employee's attitude as significant variables of research (Saini, 2006). It is also concluded in that research to fill gap between stated policies and real practices of HRM is causing employee's frustration in developing economies because HRM Model of developed economies are tested in developed economies may not be imported because of align nature of such models.

This study is prepared to address research questions including, what role SHRM plays in HR outcomes and Performance measures at individual and organizational level? More specifically SHRM relations with job satisfaction and organizational commitment (i.e. HR outcomes) and organizational and, individual performance (i.e. performance measures) using resource based view along universal perspective of SHRM has been theorized and tested.

\subsection{Literature Review}

Roots of Strategic HRM in early nineties at US companies (Lengnick-Hall et. al, 2009). The scholars classify HRM in three categories i.e. international/universal, micro/functional and strategic/macro. The roots of this concept also emerge from labour economics (Snell, 1992). Although SHRM is considered to be emerging yet without pragmatic preview of Personal management and Human Resource Management (HRM) cannot be ignored while conceptualizing about SHRM. HRM as research field is also an outcome of human relations movement and Industrial and Labor Relations concept evolved during early twenties after emergence of scientific management by Management's father Taylor (Becker \& Gerhart, 1996). Researchers further states that Initial efforts were made to recognize the Human rights in the organization by defining working hours, salary for employees instead of forced, role of unions etc. Eventually in late twenties personal management field evolved and a paradigm shifted towards HRM. Becker \& Gerhart defend the concept of HR Champions, role of HR managers to replace the union leaders. This was the time, when the Organizational Behavior researchers started thinking about micro level issues of staff by discussing employee's issues related to Job satisfaction, motivation, retention etc with the integration of applied psychology and sociology in the organizational context (Wright, \& McMahan, 1992). Eventually in modern economies like USA, Europe and UK, HRM established as emerging field to retain completive employees to be market leaders (Wright \& Snell, 1998). Subsequently the companies with routes at developed economies extended the business in developing economies and applied HRM models in emerging markets like China, India and Pakistan (Khilji, 2003; Saini, 2006; Saleem, 2012). Khilji (2003) the most cited author in Pakistani context says that, there is a need to explore concept 
of HRM reality and relevance in Pakistani context. Khilji (2003) observed that recent trends in business environment of governmental initiatives towards privatization have changed the scenario of employment trends. More recently emergence of service sector is creating big change in Pakistani business work environment. The well groomed financial instituted after reforms by state bank and Government of Pakistan (Saleem \& Khurshid, 2014), the growth and maturity of telecommunication business (Saleem \& Saleem, 2014) in less than a decade time of early twenty first century, establishment of road infrastructure to facilitate local traveling businesses after introduction of word class services like Dawoo Pakistan are few examples that have shifted HRM trends and has challenged local status co of 'SHAITH' Culture (Local owner like any Landlord). This new softer look of HRM has created challenged as well as opportunities for organization to develop and sustain the business in Pakistani economy not only by giving employees fundamental right to live, but also forced local organizations to give staff respect and motivation to achieve competitive advantage by adopting convergence towards latest HR trends (Shahzad et. al, 2008).

Lengnick-Hall et al. (2009) claim that organizations can find high level significance of HRM, if strategic choice is well integrated with functional choices of HRM e.g. cost leadership/reduction, quality improvement/analyzer, and innovation/prospector. For example the company having innovative strategy may chose to invest in training the executives while the cost leader may hired already trained executives to focus on in primary business. Similar a defender may be hired the senior management from market leader instead of training them. Thus matching strategic choice of running business in industry with HR strategy can be called strategic HRM. Scholars have diverse views regarding SHRM. Accordingly SHRM is the strategic management of human resources at macro-level while HRM is mainly concentrate on the departmental and functional issues within organization (Becker \& Gerhart, 1996). Thus main objective of SHRM can be to integrate with business strategy for better organizational performance by taking care of soft HRM issues like turnover, motivating employees and job stratification.

\subsection{Contextualized Strategic HRM Model}

Classically Strategic HRM is defined as integration between organizational strategy and human resource management practices (Snell, 1992; Wright \& Snell, 1998). Alternatively theoretical foundation of Strategic HRM embark upon the significance of human resource as significant firm's capital as financial capital (Lengnick-Hall et. Al, 2009). This theoretical assumption of Strategic HRM is build upon the foundation of resource based view. This study has adopted resource based view as foundation to build the theoretical base to develop the model. Once we are agreed that the human is critical resource then it can be further assumed that critical resource can add value for enhanced firm's performance through satisfied employees. According to HRM scholars, Strategic HRM foundation can enhance HR and performance indicators of company (Wright, \& McMahan, 1992; Saleem \& Saleem, 2014). The theoretical framework also shows that Strategic HRM has a positive and direct impact on performance (i.e. organizational and individual performance) and HR outcome (organization commitment, job satisfaction) variables (Green, et. al, 2006; Wright \& Snell, 1998). It means that SHRM is the key independent measure that ultimately helps the firm in achieving its goals strategically (Green, et al., 2001).

Performance measures are direct indicators of the firm continuous survival. These performance indicators have been used classically by scholars to link HRM with firm's performance to study the casual relationship (Delery \& Doty, 1996; Huselid, 1995). Firm's 
performance can be measured in terms of individual and company's performance (Wright, \& McMahan,1992). Green et. al (2006) state that to compute the performance of the organization one can use actual as well as perceived measures e.g. return on asset can be used as actual measure. As for as perceived measures are concerned Performance can include factors such as efficiency, customer service, productivity of employees \& their work quality (Huselid \& Becker, 1996). These things are taken as essential to achieve organization performance in the sense that the higher degree of satisfaction, better customer service, high productivity \& the better quality. In business world, company's performance analyzed at three levels that are their financial performance, their market performance \& the performance of the shareholders (Huselid, 1995). Organization performance in this study is taken as dependent variable and one of component of performance measure. Second measure of performance measure is Individual performance (IP). IP plays influencing role in all the organizations. An important assumption is the individuals are responsible and accountable for how things are done in their respective organizations. Researchers say that organizational performance can be increased by drastic enhancement of individual performance (Snell, 1992; Green et al, 2006).

HR Outcomes can be measured in terms of job satisfaction and organizational commitment (Green et al, 2006; Saleem \& Saleem, 2014). The idea behind measuring this performance indicator is that usually satisfied workforce is committed with firm to add real value which intern enhance the firm's performance. Organizational commitment is defined as a degree to which employee is willing to stay with company. In 1990 Allen \& Meyer classified commitment into three subtypes i.e. continuance, normative and affective. Nonetheless OC it is accepted that greater the OC more will be because of SHRM. Allen \& Meyer (1990) also claim that measurement of OC can be done through identifying emotional attachment of employees, commitment with assistant employees that the cost of employee leaving the organization and an employee obligation to remain in the organization. Second HR outcome used for this study is job satisfaction, which is defined as extent to which employee is happy with job as well as work context. Job satisfaction can be greater, if polices of promotion for employees is supportive in the organization. Interaction with co-workers also lead to higher job satisfaction in a way that how extremely employees are giving importance to their relationship with each other (Locke, 1969). Therefore follow research hypotheses have been developed.

HR: Adopting Strategic HRM in company affects the HR outcomes (Job Satisfaction and Organizational Commitment) and Performances Measures (individual and Organizational).

HR1: Adopting Strategic HRM in company enhances the HR outcomes

HR1a: Strategic HRM enhances organizational performance

HR1b: strategic HRM motivates individual for better performance

HR2: Adopting Strategic HRM in company enhances Performances Measures in company HR2a: Strategic HRM enhances Organizational Commitment among employees HR2b: strategic HRM increases Job Satisfaction among employees 
Figure 1: Research Model

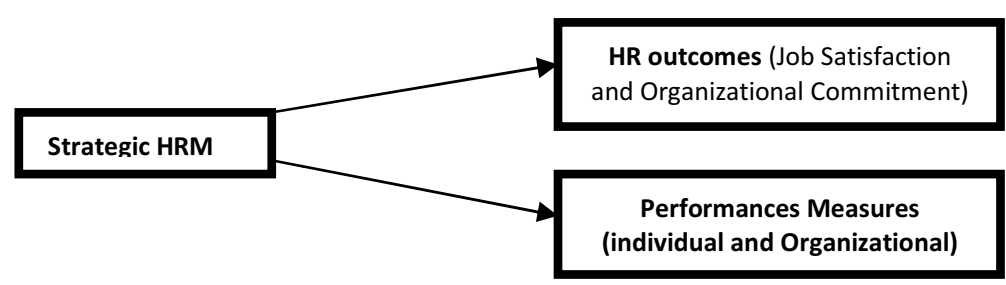

\subsection{Research Strategy}

The objectivism has been inducted for ontological assumption whereas positivism (i.e. statistical techniques of correlation and regression) has been adapted to test the epistemological assumption of research philosophy to prove the nature of reality about SHRM in local context. The population of the research study include two organizations. Initially five organizations where identified shown willingness and claiming to adopt SHRM. However three organizations finally participated. For this study only two organizations are chosen based on statistically significant result one organization is dropped because of statistically insignificant results.

First case study is a large company consisting of 450 management level employees is manufacturing company and deals in packing services. Individual manager, responding to the questionnaire is the subject element of the study. The sample size of 125 employees is chosen randomly from the target population to whom questionnaires were given and 91 employees filled the questionnaire which shows the response rate of $73 \%$. Second case study is a medium company deals in textile products locally and internationally. Company has more than 800 employees and has approximately 100 managerial level employees. The sample size of all 100 employees is chosen randomly from the target population to whom questionnaires are given and 70 employees filled the questionnaire which shows the response rate of $70 \%$.

\subsection{Measurement of concepts}

Six-item Strategic HRM scale and Seven-item scale organizational performance is adopted from by Green et al (2001, 2006). Five-item individual performance scale is developed for this study. Nine item scale of organizational commitment scale is adopted from Mowday et al. (1979) and nineteen-item scale of job satisfaction scale is adopted from Brayfield and Rothke (1951) were incorporated in the survey. Refer to table 1, items have been revalidated. Dependent variable organizational performance (OP) seven-item scale is used and Cronbach's alpha $(C X)$ for all seven items 0.761 for case study 1 and 0.872 for case study 2 , whereas Green et al. (2006) has reported 0.94 reliability for OP. Individual performance (IP) is also dependent variable. $\boldsymbol{U}$ for five-item scale is 0.546 for first case and 0.815 for case study2, which is quite low for case study 1 while better for send study. However Green et al (2006) reported 0.79 for IP, thus same items are used for data analysis. For Organizational Commitment (OC), nine-item scale is used. $\boldsymbol{U}$ is 0.802 and 0.815 for study 1 and 2 respectively, which is closer in values reported by Green et al, (2006) i.e. 0.88 for OC. Job satisfaction (JS)is also dependent variable. $\boldsymbol{L} \boldsymbol{V}$ for Nineteen-item scale which for this study is 0.623 and 0767 for two studies. Green et al (2006) reported 0.87 for JS. Thus all items are used for analysis of two studies. The only independent variable of the study is Strategic 
HRM. Six-item scale $\alpha^{\prime}$ value is 0.764 and 0.703 , which is closer to value reported by Green et al, 2006 i.e. 0.81 . Thus based on reliability analysis and all five concepts are found reliable for further analysis.

Table 1: Reliability Analysis

\begin{tabular}{lll}
\hline Concept Name & Case Study 1 $(\mathrm{n}=125)$ & Case Study 2 $(\mathrm{n}=70)$ \\
1. Organizational Performance & $(0.761,7,0)$ & $(0.872,7,0)$ \\
2. Individual Performance & $(0.546,5,0)$ & $(0.815,5,0)$ \\
3. Organizational & $(0.802,9,0)$ & $(0.851,9,0)$ \\
Commitment & & \\
4. Job Satisfaction & $(0.623,19)$, & $(0.767,19,0)$ \\
5. Strategic HRM & $(0.764,6,1)$ & $(0.703,6,0)$ \\
\hline
\end{tabular}

Notes: (Cranach's alpha, Number of Items, Number of items removed)

\subsection{Research Findings}

On the epistemological assumption, positivism has been adopted for analysis of this study. Statistical techniques of correlation and regression and been incorporated for testing the hypotheses at two companies using SPSS 17. The data is collected from three companies. However one case study is dropped consisting of 30 managerial response of a small manufacturing company of 457 employees because none of hypnotised relationship among variables was proven to be statistically significant. However based on remaining two case studies, study scholarship implies that effective Strategic HRM adoption can help company to enhance the work attitudes' of staff along with the overall performance of the organization. Subsequent section presents quantitative evidence from selected companies. The study has extended universal perspective of Strategic HRM and thus accepts that HR paradigm is shifting to prove HR as strategic business partner.

Table 2: Correlation Analysis

\begin{tabular}{lcc}
\hline Variable Name & Case Study 1 $(\mathrm{n}=125)$ & Case Study2 $(\mathrm{n}=70)$ \\
\hline 1. Organizational Performance & $0.212^{*}$ & $0.371^{* *}$ \\
2. Individual Performance & 0.168 & $0.477^{* *}$ \\
3. Organizational Commitment & $0.330^{*}$ & 0.092 \\
4. Job Satisfaction & 0.160 & 0.199 \\
5. Strategic HRM & 1 & 1 \\
\hline
\end{tabular}

Notes: Strategic HRM (Independent Variable)

$1-4$ on all four dependent variables (regressed); ${ }^{*} \mathrm{p}<0.01 * \mathrm{p}<0.05$; (p-values);

Case Study 1: Refer to table 2, correlation matrix give answers about statistical relationship between variables under case1. A positive relationship between Strategic HRM and Organizational Performance i.e. $0.212(\mathrm{p}<0.05)$, Strategic HRM and Individual Performance i.e. $0.285(p<0.01)$, Strategic HRM and Organizational Commitment i.e. $0.382(p<0.01)$ are statistically significant. According to regression result (table 3) $4.5 \%$ significant variation in organizational performance through strategic HRM with R-square value of $0.045(p<0.05)$. $14.6 \%$ variation in organizational commitment is explained through strategic HRM $(p<0.05)$. $8.1 \%$ variation in individual performance is explained through strategic HRM $(p<0.05)$. Finally variation explained in strategic HRM through Job Satisfaction is statistically insignificant 
Case Study 2: Refer to table 2, correlation matrix give answers about statistical relationship between variables under case 2. A positive correlations between Strategic HRM with Organizational Performance i.e. $0.371 \quad(\mathrm{p}<0.01)$ and Individual Performance i.e. 0.477 $(\mathrm{p}<0.01)$ are statistically significant. However for case study 2, Strategic HRM relation with and JS and OC are positive but statistically insignificant for study2. According to regression result presented in table 3, 13.8\% significant variation in organizational performance through strategic HRM with R-square value of $0.138(\mathrm{p}<0.05) .22 .7 \%$ variation in IP is explained through strategic HRM $(\mathrm{p}<0.05)$.

Table 3: Regression Analysis

\begin{tabular}{|c|c|c|c|c|}
\hline \multicolumn{5}{|c|}{ Case Study $1 \quad(n=125)$} \\
\hline Variables & Constants & Beta & S.E. & $\mathbf{R}^{2}$ (p-value) \\
\hline 1. Organizational & 2.945 & 0.212 & .099 & $.045 *(.043)$ \\
\hline \multicolumn{5}{|l|}{ Performance } \\
\hline 2. Individual Performance & 3.102 & 0.285 & .076 & $.081 *(.006)$ \\
\hline 3. Organizational & 2.376 & 0.382 & .090 & $.146 * *(.000)$ \\
\hline \multicolumn{5}{|l|}{ Commitment } \\
\hline 4. Job Satisfaction & 3.167 & 0.044 & .062 & $.002(.679)$ \\
\hline \multicolumn{5}{|c|}{ Case Study $2(n=70)$} \\
\hline 1. Organizational & 2.489 & 0.371 & 0.129 & $0.138 * *(.002)$ \\
\hline \multicolumn{5}{|l|}{ Performance } \\
\hline 2. Individual Performance & 2.581 & 0.106 & 0.477 & $0.227 * *(.000)$ \\
\hline 3. Organizational & 3.839 & 0.092 & 0103 & $0.092(.448)$ \\
\hline \multicolumn{5}{|l|}{ Commitment } \\
\hline 4. Job Satisfaction & 2.769 & 0.199 & 0.092 & $.040(.099)$ \\
\hline
\end{tabular}

Notes: Strategic HRM (Repressor ); Four dependent variables (regressed); $* * \mathrm{p}<0.01 * \mathrm{p}<0.05 ;$ ( $\mathrm{p}$-values);

\subsection{Conclusion}

Research has extended universal Strategic HRM trends through implication of recourse based HRM view as one of theoretical implication. Second the study has collected data from developing economy which us useful to attract foreign investors for financial decision about involvement in developing economies acquiring international HR trends for sustainable competitive advantage. Research was designed to identify effect of Strategic HRM on HR outcomes and performance measures of organization. The study has explored Strategic HRM effect on selected organizations. Results have theoretical and practical implications. Theoretical implications of study emphasize the significance of Strategic HRM. Research has extended universal Strategic HRM trend through implication of recourse based HRM view as one of theoretical implication. The companies that align HR function and practices perform better and produce satisfied and committed employees for enhanced individual and organizational performance. These results are relatively consistent with the findings of Green et al (2006) because study also presented positive relationship between strategic HRM and organizational performance, job satisfaction, individual performance and organizational commitment. Nonetheless job satisfaction shows statistically insignificant relation with Strategic HRM which is inconsistent with Green et al (2006). Study also extends older study of Khilji (2003) conducted in Pakistani setting in the area of HRM. Study has accepted that paradigm has also started shifting in developing economies as role of HR is shifting from operational utility to strategic business partner. Practical implication of study 
highlights that HR should strategic business partner like any other department because strategic HR role is equally critical for organizational success as marketing, finance, operations etc. Practitioners are encouraged to adopt Strategic HRM with the trust that company's performance will be improved. Further, practitioners can expect improvements in HR outcomes and job-related attitudes including employee's satisfaction, commitment and performance at individual level. Limitations of study is that data is collected from manufacturing companies shown willingness for participation based on self assessment as active actor of Strategic HRM. Sample size chosen for the study is also consists of willing employees. Secondly, Macro level variable of Strategic HRM is insufficient to predict the true picture of relationship between Strategic HRM and HR outcomes and performance measures. Thus comprehensive future research can be conducted by including more variables for classifying Strategic HRM into horizontal and vertical fit. Increased sample size for data collection from various manufacturing firms for getting more precise results. Scholarship of study implies that effective Strategic HRM can help to enhance the work attitudes' of staff along with the overall performance of the organization. The organizations at developing economies need to adopt Strategic HRM for enhanced HR outcomes and better performance measures. Performing organizations thus can always take part for economic growth of society by producing conclusive work environment, employment opportunities and addressing societal needs of goods and services at large. 送

\section{References}

Allen, N. J., \& Meyer, J. P. (1990). The measurement and antecedents of affective, continuance and normative commitment to the organization. Journal of Occupational Psychology, 63(1), 1-18.

Becker, B., \& Gerhart, B. (1996). The impact of human resource management on organizational performance: Progress and prospects. Academy of Management Journal, 39(4), 779-801.

Brayfield, A.H. and Rothke, H.F. (1951). An Index of Job Satisfaction', Journal of Applied Psychology, 35(5), 307-311.

Delery, J. E., \& Doty, D. H. (1996). Modes of theorizing in Strategic Human Resource Management: Tests of universalistic, contingency and configurational performance predictions. Academy of Management Journal, 39(4), 802-835.

Green, K. W., Wu, C., Whitten, D., \& Medlin, B. (2006). The impact of strategic human resource management on firm performance and HR professionals' work attitude and work performance. The International Journal of Human Resource Management, 17(4), 559-579.

Green, Jr., K.W., Medlin, B. and Medlin, R. (2001) 'Strategic Human Resource Management: Measurement Scale Development', Academy of Strategic and Organizational Leadership Journal, 5(2), 99-112.

Huselid, M.A. (1995). The Impact of Human Resource Management Practices on Turnover, Productivity, and Corporate Financial Performance. Academy of Management Journal, 38(3), 635-670.

Huselid, M.A. and Becker, B. (1996). Methodological Issues in Cross-Sectional and Panel Estimates of the Human Resource-Firm Performance Link. Industrial Relations, 35(3), 400422. 
Khilji, S. E. (2003). To Adapt or Not to Adapt'Exploring the Role of National Culture in HRM-A Study of Pakistan. International Journal of Cross Cultural Management, 3(1), 109132

Khilji, S. E., \& Wang, X. (2006). 'Intended' and 'implemented' HRM: the missing linchpin in strategic human resource management research. The International Journal of Human Resource Management, 17(7), 1171-1189.

Lengnick-Hall, M. L., Lengnick-Hall, C. A., Andrade, L. S., \& Drake, B. (2009). Strategic human resource management: The evolution of the field. Human Resource Management Review, 19(2), 64-85.

Locke, E.A. (1969). What is Job Satisfaction? Organizational Behavior and Human, 4(1), 309-336.

Mowday, R.T., Steers, R.M. and Porter, L.W. (1979). The Measurement of Organizational Commitment, Journal of Vocational Behavior, 14(2), 224-247.

Saleem I (2012). Impact of adopting HRIS on three tiers of HRM Evidence from Developing Economy, Business Review, 7(2), 96-105.

Saleem I. \& Khurshid A. (2014). Do Human Resource Practices affect Employee Performance?, Pakistan Business Review, 15(4), 669-688

Saleem I. \& Saleem N. (2014). Mediating role of job satisfaction: Using new evidence to reconcile an old debate, Journal of Behavioural Sciences, 24(1), 130-149

Saini D.S. (2006), Managing employee relations through Strategic Human Resource Management, Indian Journal of Industrial Relations, 42(2), 170-189.

Shahzad, K., Bashir, S., \& Ramay, M. I. (2008). Impact of HR practices on perceived performance of university teachers in Pakistan. International Review of Business Research Papers, 4(2), 302-315.

Snell, S. A. (1992). Control Theory in Strategic Human Resource Management: The Mediating Effect of Administrative Information. The Academy of Management Journal, 35(2), 292-307.

Wright, P. M., \& McMahan, G. C. (1992). Theoretical perspectives for strategic human resource management. Journal of management, 18(2), 295-320.

Wright, P. M., \& Snell, S. A. (1998). Toward a unifying framework for exploring fit and flexibility in strategic human resource management. Academy of Management Review, 23(4), 756-772.

". . . In the world a man must behave as other people behave, and hat if he allows his conduct to be guided by the thought of what men ought to do, this will conduce rather to his ruin than to his advantage or preservation."

Herbert Butterfield, The Statecraft of Machiavelli, p.84 